\title{
Optimizing Bookstore Production Using Fuzzy Linear Programming
}

\author{
Suzanawati Abu Hasan ${ }^{1 *}$, Teoh Yeong Kin², Nur Salsabila Abd Rahman², Diana Sirmayunie Mohd \\ Nasir $^{4}$ \\ ${ }^{1,2,3,4}$ Faculty of Computer and Mathematic Sciences, Universiti Teknologi MARA Perlis Branch, Malaysia \\ Corresponding author: *email address \\ Received Date: 11 August 2018 \\ Accepted Date: 12 November 2018
}

\begin{abstract}
The world Reader bookstore has a structured collection of books neatly arranged on shelves. The question is how the bookstore should keep the shelves full and make profit at the same time. Books are expensive due to the building tax that the business owner needs to pay, along with the tax imposed on each book. Hence, a bookstore owner will typically increase the prices of the books to make profit. Due to the high prices, people are keener to buy books through online store. Thus, this study is conducted to optimize books needed to be sold in a bookstore using the fuzzy linear programming approach. This study will focus more on fiction and non-fiction books that are available in the bookstore, which will help the bookstore to achieve its highest profit in the future. The result shows that the profit in a closed interval of [RM209016.00, RM348691.20] was obtained once the fiction and non-fiction books were [0 unit, 8000 units] and [4000 units, 4000 units]. Based on the findings of the study, other businesses can also use this method in to optimize their business in the future.
\end{abstract}

Keywords: Optimizing, Bookstore Production, Fuzzy Linear Programming

\section{INTRODUCTION}

In the hustle and bustle of daily life, the bookstore is a place where people could go and find relaxation time for themselves. Information, and entertainment can be found in a bookstore. There are usually many sections in a bookstore, such, fiction, non-fiction, education (including sections for SPM, PT3 and UPSR), language, art, technology, business and sections for stationaries, comics, and many more.

An interesting question is how a bookstore should keep its shelves full and make profit at the same time. In this situation, mathematical modelling can be a big help to maximize the profit earned by a bookstore. Profit is the single biggest determinant of whether a store succeeds commercially or fails. According to the CEO of Idea Logical Company, (Shatzkin, 2009), a bookstore must guess which books to order at a specific time. Therefore, this study will focus on maintaining sales despite not knowing what suit readers the most. In this modernized era, people are more attracted to technology. Books can be purchased online with a single click. Furthermore, technological devices are getting more sophisticated day by day, hence books can be accessed everywhere and anytime. Consequently, opening a bookstore is a risky business. Thus, an important factor to consider is the strategy that booksellers should use to keep up with the technology to maintain or increase sales.

People are still buying books from the bookstore because some find the smell of a new book being opened from its packaging exhilarating. The existence of a bookstore is important for future generation to experience reading physical books. A bookstore is helpful for people to expand knowledge. This study aims to help a bookstore optimize its production and avoid books from being untouchable on the shelves. 


\section{LINEAR PROGRAMMING}

Linear Programming (LP) is a special case of a mathematical programming problem. From an expert's point of view, an LP problem is a mathematical program that can identify minimum or maximum point of a function and also satisfies a set of constraints. The problem constraints are linear and linear programming work as the objective's function. A crisp linear programming model or classical model of LP may have the following formulation, whereby $x_{\text {is a }} n \times 1$ alternative set, $C^{\prime}$ is a $1 \times n$ coefficients of an objective function, $A i$ is a $m \ltimes n_{\text {matrix of coefficients of constraints and } b i \text { is a } m \times 1 \text { right-hand sides (Guney, Teke }}$ and Tas, 2016).

\section{FUZZY LINEAR PROGRAMMING}

Zimmermann first introduced the fuzzy set theory into linear programming problems in 1976, and linear programming problems with a fuzzy goal and fuzzy constraints was considered (Sakawa, Yano and Nishizaki, 2013). Fuzzy linear programming (FLP) is often insufficient in practical situations which follow classical linear programming but fuzzy feasible solution is said to be a fuzzy optimal solution (Ebrahimnejad, 2011). As a matter of fact, certain coefficients that appear in classical LP problems may not be well-defined. This is because their values depend on other parameters or because they cannot be accurately evaluated and only qualitative estimates of these coefficients are available. Fuzzy linear programming is an addition of classical linear programming and deals with vague coefficients by using fuzzy variables. The fuzzy linear programming problem can be written as:

\section{$\operatorname{Ma} \tilde{z}=\widetilde{C}^{\top} x$}

St.

$\widetilde{A} x \widetilde{b}$

$x \geq 0$.

The possibility distribution of the optional objective function $Z_{\text {is }}$ the solution to this problem. Researchers that use this method had handled this problem by converting the fuzzy objective function and the fuzzy constraints into crisp ones (Guney, Teke and Tas, 2016).

\section{PRODUCTION DATA}

Table 1 shows the secondary data of selling, productions and availability of inventory stock of books in the bookstore.

Table 1: Selling, productions and availability of inventory stock of books in the bookstore

\begin{tabular}{|l|l|l|l|}
\hline Category & Books & \\
\cline { 2 - 4 } & Fiction & Non-fiction & Availability \\
\hline Price, RM (million) & & & \\
\hline Recorded Books Bought from Publisher for a year (000 units) & & & \\
\hline Number of books sold for a year (000 units) & & & \\
\hline Number of books sold per person for a year (000 units) & & & \\
\hline Inventory stock input for a year (000 units) & & & \\
\hline Inventory stock output for a year (000 units) & & & \\
\hline
\end{tabular}


The information from Table 1 will be translated into the fuzzy linear programming problem with the aim to obtain the maximum profit earned by the bookstore (Abdullah and Abidin, 2014).

\section{STEPS TO OBTAIN MAXIMIZATION PROFIT}

Step 1: Write linear programming problem.

Assign the variable to each $x_{1}$ and $x_{2}$; where $x_{1=\text { fiction books and }} x_{1=\text { non-fiction books. The objective }}$ function for the problem is created by adding the profit of each type of books for the studied year to the optimal profit. The full linear programming form can be produced in following structure.

$$
\begin{array}{ll}
\text { Maximize } & Z=\widetilde{h} x_{1}+\widetilde{h} x_{2} \\
\text { Subject to } & \tilde{d}_{1} x_{1}+\tilde{d}_{12} x_{2} \leq \widetilde{e}_{1} \\
& \widetilde{d}_{21} x_{1}+\widetilde{d}_{22} x_{2} \geq \widetilde{e}_{2} \\
& \widetilde{d}_{31} x_{1}+\widetilde{d}_{32} x_{2} \leq \widetilde{e}_{3} \\
& x_{1}, x_{2} \geq 0
\end{array}
$$

The constraints can be defined as

$$
\begin{aligned}
& \tilde{d}_{1,}, \widetilde{d}_{12=\text { recorded books bought from publisher }} \\
& \tilde{d}_{2,}, \widetilde{d}_{22=\text { number of books sold }} \\
& \tilde{d}_{31}, \widetilde{d}_{32}=\text { number of books sold per person } \\
& \widetilde{e}_{1}, \widetilde{e}_{2}, \widetilde{e}_{3}=\text { availability }
\end{aligned}
$$

Step 2: Obtain the optimal value of the problem in Step 1.

Linear programming software can be used to obtain the optimal values for the problem. This study will use solver in Microsoft Excel 2013.

Step 3: Create fuzzy numbers for coefficients

The fuzzy numbers for each coefficient are calculated based on the crisp amount in Table 1

Step 4: Form the fuzzy linear programming problem.

This step used Eq. (3.2) to form the fuzzy linear programming problem.

Step 5: Outline the sub-problem of objective linear programming problem.

The fuzzy linear programming problem will be split into eight sub-problems of crisp linear programming which is taken from step 4. The fuzzy optimal solution with highest membership degree can be obtained by solving the developed crisp linear programming problem (Oh, Lee and Song, 2015)

Step 6: Obtain the optimal solution for the sub-problems. 
Linear programming solver is used to obtain the optimal solutions of the sub-problems.

Step 7: Find the upper and lower bound ( $U_{k}$ and $L_{k}$ ) from the objective value obtained in Step 6.

Step 8: Create initial fuzzy model with value of aspirations and maximize it.

Step 9: Obtain optimal value.

The values of $x_{1}, x_{2}$ and $Z$ can be obtained by setting the value of aspiration, $\lambda_{\text {Fuzzy linear }}$ programming yields a number of optimal solutions depending on the flexibility of aspiration values. The maximum profits of books are varied depending on the value of aspiration, and variables of books (Abdullah and Abidin, 2014).

\section{RESULTS AND DISCUSSIONS}

\section{Results Analysis}

Table 2: The data from World Reader bookstore was analysed.

\begin{tabular}{|l|l|l|l|}
\hline \multicolumn{1}{|c|}{ Category } & \multicolumn{2}{|c|}{ Books } & Non-fiction \\
\cline { 2 - 4 } & \multicolumn{1}{|c|}{ Fiction } & Availability \\
\hline Price, RM (million) & 0.04942 & 0.023224 & \\
\hline $\begin{array}{l}\text { Recorded Books Bought from } \\
\text { Publisher for a year (000 units) }\end{array}$ & 11.232 & 4.368 & \\
\hline $\begin{array}{l}\text { Number of books sold for a year } \\
\text { (000 units) }\end{array}$ & 9.884 & 2.903 & \\
\hline $\begin{array}{l}\text { Number of books sold per person } \\
\text { for a year (000 units) }\end{array}$ & 0.02 & 0.04 & 15.6 \\
\hline $\begin{array}{l}\text { Inventory stock input for a year } \\
\text { (000 units) }\end{array}$ & & & 2.813 \\
\hline $\begin{array}{l}\text { Inventory stock output for a year } \\
\text { (000 units) }\end{array}$ & & & \\
\hline
\end{tabular}

Table 3: Optimal solution with different value of aspiration.

\begin{tabular}{|l|l|l|l|}
\hline Value of aspiration, $\lambda$ & \multicolumn{1}{|c|}{ Fiction, $\boldsymbol{x}_{1}$} & \multicolumn{1}{c|}{ Non-Fiction, $\boldsymbol{x}_{2}$} & $Z$ \\
\hline 0.3 & 0 & 8000 & 209016.00 \\
\hline 0.5 & 1000 & 7000 & 254385.60 \\
\hline 0.7 & 2000 & 6000 & 285820.80 \\
\hline 0.9 & 3000 & 5000 & 317256.00 \\
\hline 1.0 & 4000 & 4000 & 348691.20 \\
\hline
\end{tabular}

If $\lambda=1$, the optimal solutions are $x_{1}=400,\left(x_{2}=400\right.$ and $Z=348692()$ The potential optimal solutions with their respected values of aspiration can be seen in Table 3 .

Fuzzy linear programming provides several optimal solutions. These optimal solutions depend on the flexibility of the aspiration values. The maximum profits of fiction and non-fiction books differ depending on the value of aspiration and the variables. 


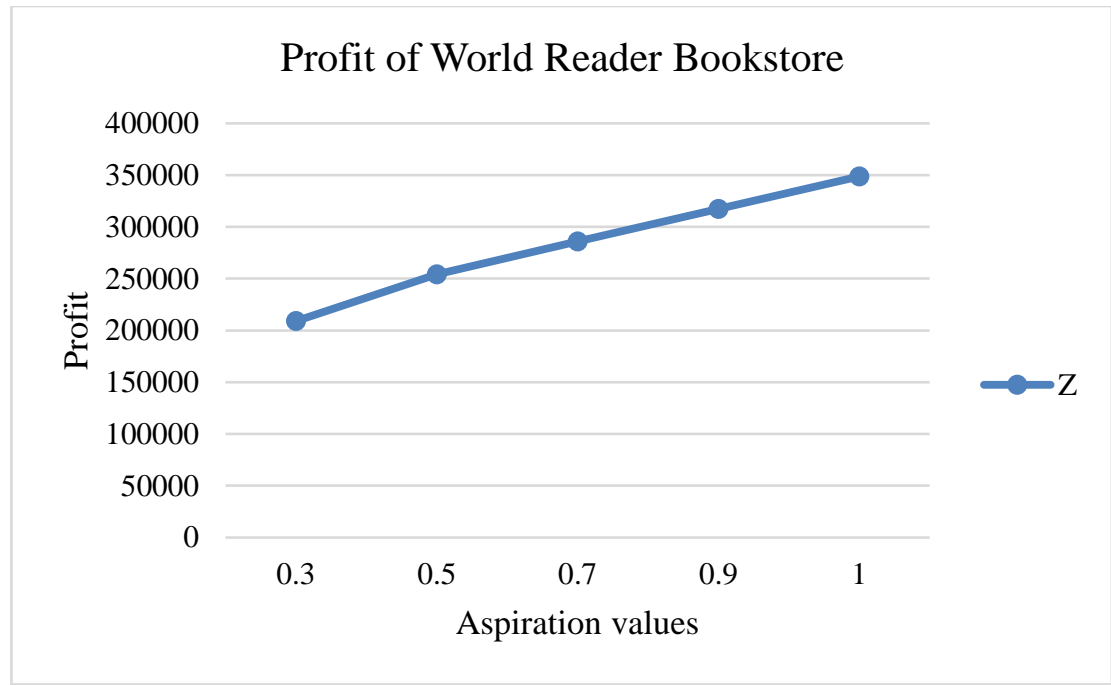

Figure 1: Trends of profit against the value of aspirations.

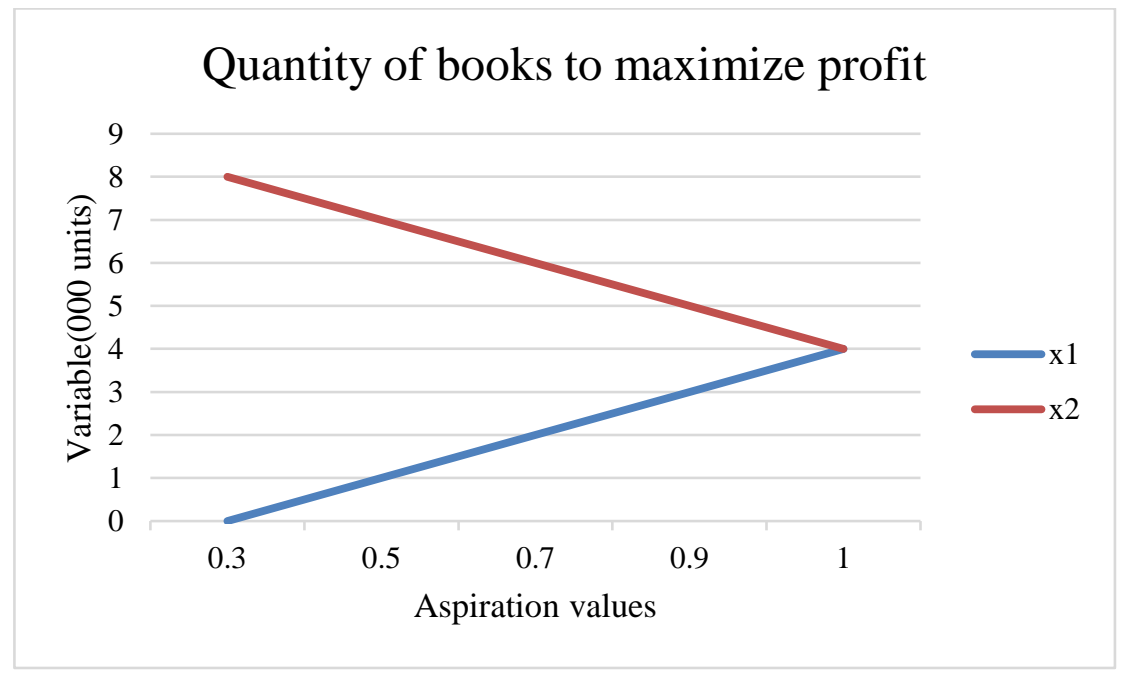

Figure 2: Trends of variables against the value of aspirations

Figure 1 shows that the profit of the World Reader bookstore increased with the value of aspiration, while Figure 2 shows the trends of the fiction and non-fiction books which indicate that the gaps between the two variables are minor once the aspiration values approach the greatest value. The optimal solution with different aspiration values was also obtained. Fuzzy linear programming produced the optimal solution if the aspiration value is in the interval $[0.3,1.0]$. The maximum profit of the same production problem using crisp linear programming was RM82942.86. This profit was demolished in the closed interval of the fuzzy profit. Fuzzy linear programming provides the result in interval value. Nevertheless, the advantage of the fuzzy results versus crisp results depends critically on the aspiration values and the defined fuzzy numbers.

This study has shown that the World Reader bookstore needs to buy 4000 units of fiction books and 4000 units of non-fiction books from the publisher to maximize profit and optimize the bookstore's production. The maximum profit that can obtain yearly by the bookstore is [RM RM209016.00, RM348691.20]. 


\section{CONCLUSIONS}

The main objective of this research to apply the fuzzy linear programming approach to optimize the bookstore's production has been achieved. Fuzzy numbers and memberships of aspiration values contributed in achieving the final results. This study showed that the maximum profit that can be obtained yearly by the bookstore is RM348691.20.

\section{REFERENCES}

Abdullah, L., \& Abidin, N. H. (2014). A fuzzy linear programming in optimizing meat production. International Journal of Engineering and Technology, 6(1).

Ebrahimnejad, A., \& Tavana, M. (2014). A novel method for solving linear programming problems with symmetric trapezoidal fuzzy numbers. Applied Mathematical Modelling, 38(17-18), 4388-4395. https://doi.org/10.1016/j.apm.2014.02.024

El-Kholy, A. M. (2014). A Multi-Objective Fuzzy Linear Programming Model for Cash Flow Management. Journal of Engineering Research and Applications Www.Ijera.Com ISSN, 4(3), 152-163. Retrieved from www.ijera.com

Hosseinzadeh Lotfi, F., Allahviranloo, T., Alimardani Jondabeh, M., \& Alizadeh, L. (2009). Solving a full fuzzy linear programming using lexicography method and fuzzy approximate solution. Applied Mathematical Modelling, 33(7), 3151-3156. https://doi.org/10.1016/j.apm.2008.10.020

Kumar, A., Kaur, J., \& Singh, P. (2011). A new method for solving fully fuzzy linear programming problems. Applied Mathematical Modelling, 35(2), 817-823. https://doi.org/10.1016/j.apm.2010.07.037

Nejad, A. M., \& Mashinchi, M. (2011). Ranking fuzzy numbers based on the areas on the left and the right sides of fuzzy number. Computers and Mathematics with Applications, 61(2), 431-442. https://doi.org/10.1016/j.camwa.2010.11.020

Sakawa, M., Yano, H., \& Nishizaki, I. (2013). Multiobjective Linear Programming. In Linear and Multiobjective Programming with Fuzzy Stochastic Extensions (pp. 73-103). https://doi.org/10.1007/978-1-4614-9399-0_3

Se-Ho, O., Myungho, L., \& Wooyoung, S. (2015). Solving a Fuzzy Linear Programming Problem with Triangular Membership Function. Indian Journal of Science and Technology, 8(S9). Retrieved from http://www.indjst.org/index.php/indjst/article/view/68287/55345

Guney, B., Tas, M., \& Teke, C. (2016). Fuzzy Linear Programming Approach for Determining The Production Amounts in Food Industry. International Journal of Engineering and Technology, 4(1).

Shatzkin, M. (2013). Buying Is a Hard Thing for Bookstores to Do Effectively, and That Becomes an Increasingly Important Reality for Publishers. The Idea Logical Company. Retrieved from https://www.idealog.com/blog/buying-is-a-hard-thing-for-bookstores-to-do effectively-and-that-becomes-anincreasingly-important-reality-for-publishers/

Se-Ho, O., Myungho, L., \& Wooyoung, S. (2015). Solving a Fuzzy Linear Programming Problem with Triangular Membership Function. Indian Journal of Science and Technology, 8(S9). Retrieved from http://www.indjst.org/index.php/indjst/article/view/68287/55345 